\title{
Análise filogenética de papilomavírus bovino associado com lesões cutâneas em rebanhos do Estado do Paraná ${ }^{1}$
}

\author{
Marlise P. Claus ${ }^{2}$, Daniel Vivian² ${ }^{2}$, Michele Lunardi ${ }^{2}$, Alice F. Alfieri ${ }^{3}$ \\ e Amauri A. Alfieri ${ }^{3 *}$
}

\begin{abstract}
Claus M.P., Vivian D., Lunardi M., Alfieri A.F. \& Alfieri A.A. 2007. [Phylogenetic analysis of bovine papillomavirus associated with skin warts in cattle herds from the state of Paraná.] Análise filogenética do papilomavírus bovino associado a lesões cutâneas em rebanhos do Estado do Paraná. Pesquisa Veterinária Brasileira 27(7):314-318. Laboratório de Virologia Animal, Departamento de Medicina Veterinária Preventiva, Centro de Ciências Agrárias, Universidade Estadual de Londrina, Cx. Postal 6001, Campus Universitário, Londrina, PR 86051-990, Brazil. E-mail: alfieri@uel.br

Bovine papillomavirus (BPV) infection causes hyperplastic lesions in the cutaneous epithelium of cattle. Six types of BPV were classified in two sub-groups, being correlated to the anatomical regions of the infection and morphologic characteristics of the lesions. The present study was carried out to identify the types of BPV present in skin warts of cattle from the state of Paraná, Brazil. The generic primers FAP59 and FAP64 were used for amplification of a 478 bp fragment of BPV L1 gene in nine cutaneous papilloma samples obtained from six animals in four herds. In all papillomas examined, a product with the expected molecular size was amplified. Phylogenetic analysis of the PCR products identified BPV-2 in three samples, BPV-1 in one, and BPV-6 in five papillomas. BPV- 6 was detected in cutaneous papillomas of the teat and in other body parts as well. In one animal, from which more than one sample was collected, a concomitant infection by BPV-1 and BPV-2 was identified. The five positive BPV- 6 samples showed a nucleotide identity of $100 \%$ with the sequence of the reference strain available in GenBank. However, differences among BPV-2 and BPV-1 Brazilian samples and the respective reference sequences deposited in GenBank were observed. Molecular comparison of the two BPV-2 strains identified showed the involvement of two viral variants. This study revealed the diversity of BPV types circulating in the state of Paraná.
\end{abstract}

INDEX TERMS: Bovine papillomavirus, cutaneous papillomatosis, phylogeny, polymerase chain reaction.

RESUMO.- A infecção pelo papilomavírus bovino (BPV) causa lesões hiperplásicas no epitélio cutâneo dos animais. De acordo com a localização e as características morfológicas das lesões, os seis tipos de BPV são classificados em dois sub-grupos. $\mathrm{O}$ objetivo desse trabalho foi identificar os tipos de BPV presentes em lesões cutâneas em bovinos de rebanhos do Estado do Paraná. Os primers degenerados FAP59 e FAP64 foram utilizados para a amplificação de um fragmento com 478 pb do gene L1 do BPV

\footnotetext{
${ }^{1}$ Recebido em 17 de novembro de 2006.

Aceito para publicação em 24 de maio de 2007.

2 Pósgraduando em Ciência Animal da Universidade Estadual de Londrina (UEL), Londrina, PR.

${ }^{3}$ Laboratório de Virologia Animal, Departamento de Medicina Veterinária Preventiva (UEL), Cx. Postal 6001, Londrina, PR 86051-990, Brasil. Tel./fax +55 (43) 3371-4714. "Autor para correspondência: alfieri@uel.br
}

bovino em nove amostras de papilomas cutâneos obtidos de seis animais provenientes de quatro rebanhos bovinos do Estado. Em todas as amostras foi possível a amplificação de um produto com a massa molecular esperada. Por meio da análise filogenética das sequiências dos amplicons foi possível identificar o BPV-2 em três amostras, o BPV-1 em uma e o BPV-6 em cinco amostras de papilomas. O BPV-6 foi encontrado tanto em papilomas localizados no teto quanto em outras partes do corpo. Em um dos animais, do qual foram colhidas mais de uma amostra, foi detectada infecção concomitante do BPV-1 com o BPV-2. As cinco amostras positivas para o BPV-6 apresentaram $100 \%$ de identidade de nucleotídeos com a amostra padrão disponível no GenBank. No entanto, foram identificadas diferenças entre as amostras do BPV-2 e BPV-1 e aquelas depositadas neste banco de dados. Esse estudo demonstrou a diversidade de tipos do BPV circulantes em rebanhos do Estado do Paraná. 
TERMOS DE INDEXAÇÃO: Papilomavírus bovino, papilomatose cutânea, filogenia, reação da polimerase em cadeia.

\section{INTRODUÇÃO}

Os papilomavírus (PV) pertencem a um grupo heterogêneo de vírus DNA epiteliotrópicos, que infectam as células basais induzindo-as à formação de lesões tumorais, conhecidas como papilomas ou verrugas, nos epitélios cutâneo e mucoso. As lesões são geralmente benignas e com tendência à regressão, mas sob condições especiais, podem se transformar em tumores malignos. A papilomatose cutânea encontra-se amplamente disseminada em todo o mundo e ocorre em diversas espécies de mamíferos e aves (Lancaster \& Olson 1982, Campo \& Jarrett 1986, Hopkins 1986).

A família Papillomaviridae é constituída por 16 gêneros e mais de uma centena de tipos virais. Até o momento, foram caracterizados apenas seis tipos de papilomavírus bovino (BPV-1 a BPV-6), que estão incluídos nos gêneros Delta-papillomavirus (BPV-1 e 2), Epsilon-papillomavirus (BPV-5) e Xi-papillomavirus (BPV-3, 4 e 6) (De Villiers et al. 2004). Mais recentemente, com o uso de métodos moleculares, foram descritos 16 supostos novos tipos virais de BPV (Antonsson \& Hansson 2002, Ogawa et al. 2004).

Considerando o tropismo celular e as lesões ocasionadas, os seis tipos de BPV podem ser classificados em dois subgrupos. $\mathrm{O}$ subgrupo A (BPV-1, 2 e 5) compreende os fibropapilomavírus, e o subgrupo B (BPV-3, 4 e 6) abrange os papilomavírus epiteliotrópicos (Campo 1997). Todos os tipos de BPV já foram identificados em papilomas cutâneos presentes em várias partes do corpo, incluindo os tetos e úbere (Bloch et al. 1997, Campo 1998, Jelínek \& Tachezy, 2005). Lesões neoplásicas na bexiga e no trato digestório superior de bovinos também são associadas com a infecção pelo BPV-2 e BPV-4, respectivamente, em associação com cofatores oncogênicos presentes na samambaia (Pteridium aquilinum) (Campo et al. 1992, Borzacchiello et al. 2001).

O genoma dos papilomavírus é constituído por uma fita dupla de DNA circular que contém 10 seqüências abertas de leitura (open reading frames - ORF), distribuídas em duas regiões principais (E e L), conforme a fase de transcrição. $O$ segmento inicial (early - E) é constituído por oito ORFs e o segmento tardio (late L) contém duas ORFs. Entre os segmentos E e L existe ainda um outro segmento denominado LCR (long control region). O segmento E codifica proteínas não-estruturais, o segmento $\mathrm{L}$ codifica as proteínas estruturais L1 e L2 e o LCR contêm elementos promotores e reguladores da replicação viral. O capsídeo viral é formado pelas proteínas L1 e L2. A proteína gênero-específica L1 é a principal proteína do capsídeo, contém epítopos que induzem anticorpos neutralizantes e, mesmo na ausência do genoma e da outra proteína, pode formar partículas semelhantes a vírions (Campo 1995, David et al. 2001).

A ORF L1 é a mais conservada no genoma do papilomavírus e tem sido utilizada para a identificação de novos tipos virais. Um novo tipo de papilomavírus é reconhecido quando o seqüenciamento da ORF L1 demonstrar diferença de identidade de nucleotídeos superior a $10 \%$. Diferenças de identidade entre 2 e $10 \%$ definem um subtipo e inferiores a $2 \%$ caracterizam uma variante viral (De Villiers et al. 2004, Bernard 2005).

Forslund et al. (1999), utilizando os primers degenerados
FAP59 e FAP64 para a amplificação parcial do gene L1, e posterior seqüenciamento do produto amplificado, descreveram 12 supostos novos tipos de papilomavírus humano (HPV). Posteriormente, essa mesma estratégia possibilitou a identificação de 16 supostos novos tipos de BPV provenientes tanto de lesões cutâneas quanto de pele saudável (Antonsson et al. 2000, Antonsson \& Hansson 2002, Ogawa et al. 2004). Esses achados sugerem que a mesma diversidade molecular já caracterizada no papilomavírus humano (HPV), entre os quais atualmente são reconhecidos mais de 200 tipos virais, também pode ocorrer nos PV de origem bovina (Bernard 2005).

O objetivo do presente trabalho foi identificar os tipos de BPV presentes em lesões cutâneas de bovinos da região norte do Estado do Paraná por meio do seqüenciamento e de análise filogenética da região do gene $\mathrm{L} 1$.

\section{MATERIAL E MÉTODOS}

\section{Origem das amostras}

Foram avaliadas nove amostras de papilomas cutâneos. Para evitar uma possível contaminação com diferentes tipos de BPV presentes em um mesmo animal, cada amostra era constituída por um único papiloma colhido assepticamente. As amostras foram provenientes de seis animais (A-F) de quatro rebanhos (1-4) bovinos dos municípios de Tamarana, São Pedro do Ivaí e Ortigueira, na região norte do Estado do Paraná. Os animais analisados eram de ambos os sexos, com aptidão mista (corte e leite) e com idade entre 20 a 32 meses. Em três animais (B, C e E) foi colhido um único papiloma e em outros três (A, D e F) foram colhidos dois papilomas por animal em diferentes regiões do corpo. Nas amostras com excesso de queratina, as porções mais externas do papiloma foram retiradas. Após a colheita as amostras foram conservadas individualmente a $4^{\circ} \mathrm{C}$ e, posteriormente, estocadas a $-20^{\circ} \mathrm{C}$ até o processamento.

\section{Extração do DNA}

Os papilomas foram triturados em PBS pH 7,2 e a suspensão $(10 \% \mathrm{p} / \mathrm{v})$ foi centrifugada por $15 \mathrm{~min}$ a $3000 \mathrm{x} \mathrm{g}$ a $4^{\circ} \mathrm{C}$. Alíquotas de $250 \mu \mathrm{l}$ do sobrenadante foram incubadas com tampão de lise $(1 \%$ Nonidet $\mathrm{P} 40,2 \%$ SDS e $0,2 \mathrm{mg} / \mathrm{ml}$ proteinase $\mathrm{K}$ ) a $56^{\circ} \mathrm{C}$ por $30 \mathrm{~min}$. Para a extração do DNA foi utilizada uma combinação das técnicas fenol/clorofórmio/álcool isoamílico e sílica/tiocianato de guanidina (Alfieri et al. 2006). As amostras foram tratadas com igual volume de fenol/clorofórmio/álcool isoamílico na proporção 25:24:1, homogeneizadas e aquecidas a $56^{\circ} \mathrm{C}$ por $15 \mathrm{~min}$ (Sambrook \& Russel 2001). Após centrifugação a $10.000 \times \mathrm{g}$ por $10 \mathrm{~min}$, a fase aquosa foi processada com sílica/tiocianato de guanidina (Boom et al. 1990). O DNA foi eluído em $125 \mu \mathrm{L}$ de água ultrapura estéril e mantido a $20^{\circ} \mathrm{C}$ até a sua utilização. Para o controle de eventuais contaminações foi incluída uma alíquota de água ultra-pura estéril em todos os procedimentos de extração do DNA.

\section{Reação da polimerase em cadeia (PCR)}

Para a amplificação parcial do gene L1 do BPV foram utilizados os primers degenerados FAP59 e FAP64 (Quadro 1), resultando em um fragmento de $478 \mathrm{pb}$ (Forslund et al. 1999).

A reação foi realizada com $2,5 \mu \mathrm{l}$ do DNA extraído, $0,4 \mathrm{pmol} / \mathrm{ml}$ de cada primer; 2,5 unidades de Platinum Taq DNA polymerase (Invitrogen ${ }^{\top \mathrm{M}}$ Life Technologies, EUA), 1x PCR buffer, 1,5 mM MgCl, $200 \mathrm{mM}$ de cada dNTP e água ultrapura estéril para o volume final de $25 \mu \mathrm{l}$. A amplificação foi realizada em termociclador nas seguintes condições de tempo e temperatura: uma etapa de $10 \mathrm{~min}$ a $94^{\circ} \mathrm{C}$, seguida de 40 
Quadro 1. Primers utilizados na reação em cadeia da polimerase para a identificação e análise filogenética do papilomavírus bovino associado a lesões cutâneas

\begin{tabular}{crc}
\hline Primer $^{\mathrm{a}}$ & Seqüência $^{\mathrm{b}}$ & nt HPV-8 \\
\hline FAP59 & 5'TAA CWG TIG GIC AYC CWT ATT 3' & 5981-6001 \\
FAP64 & 5' CCW ATA TCW VHC ATI TCI CCA TC 3' & 6458-6436
\end{tabular}

a Fourslund et al. 1999.

b Nucleotídeos degenerados : $\mathrm{W}=\mathrm{T}, \mathrm{C}$; $\mathrm{I}=\operatorname{Inosina} ; \mathrm{Y}=\mathrm{C}, \mathrm{T} ; \mathrm{V}=\mathrm{A}, \mathrm{C}, \mathrm{G} ; \mathrm{H}=\mathrm{A}$, T, C.

ciclos de $1 \mathrm{~min}$ a $94^{\circ} \mathrm{C}, 1 \mathrm{~min}$ a $50^{\circ} \mathrm{C}, 1 \mathrm{~min}$ a $72^{\circ} \mathrm{C}$ e uma etapa final de $7 \mathrm{~min}$ a $72^{\circ} \mathrm{C}$. Alíquotas de $8 \mathrm{ml}$ dos produtos amplificados foram submetidas à eletroforese em gel de agarose a $2 \%$ com brometo de etídio $(0,5 \mathrm{mg} / \mathrm{ml})$ em TBE $\mathrm{pH} 8,4$ sob voltagem constante $(90 \mathrm{~V})$ por aproximadamente $45 \mathrm{~min}$. O gel foi visualizado sob luz UV.

\section{Seqüenciamento e análise das seqüências}

Os produtos da PCR foram purificados utilizando os kits comerciais GFX PCR DNA e Band Purification (GE Healthcare) e posteriormente seqüenciados com o kit DYEnamic ET Dye Terminator (GE Healthcare), em sequienciador automático MegaBACE 1000 (GE Healthcare), com os primers forward e reverse. A qualidade das sequiências obtidas foi avaliada pelos softwares Phred/Phrap/Consed Analysis Program (http:/ /www.phrap.org/phredphrapconsed.html) e a identidade dos produtos foi comparada com as sequiências depositadas em bases públicas de dados (GenBank - National Institute of Health, Bethesda, MD, EUA) utilizando o software BLAST (http://www.ncbi.nlm.nih.gov/BLAST).

Para a definição de subtipos e variantes de PV foi utilizado o critério do Comitê Internacional de Taxonomia de Vírus (ICTV).

\section{Alinhamento das sequiências e análise filogenética}

$\mathrm{O}$ alinhamento das sequiências de nucleotídeos e o percentual de identidade com as sequiências previamente determinadas de estirpes padrão do BPV-1 a 6, HPV-16 e 19 e COPV (canine oral PV), foi estimada usando o software BioEdit 7.0.5 (Ibis Therapeutics, Carlsbad, CA, EUA) (Hall, 1999). A análise filogenética de distância foi calculada usando o modelo evolutivo Kimura 2 - parâmetro e o algoritmo neighbor-joining, com suporte de bootstrap para 1000 réplicas, utilizando o programa Mega 3.1 (Kumar et al., 2004)

\section{Número de acesso das seqüências de nucleotídeos}

Os números de acesso no GenBank dos diferentes tipos de PV utilizados para as análises filogenéticas são: BPV-1 (AY312992), BPV-2 (MZ20219), BPV-3 (NC004197), BPV-4 (X05817), BPV-5 (NC23217014), BPV6 (AJ620208), HPV-16 (DQ469930), HPV-19 (X74470), COPV (NC001619).

Quadro 2. Distribuição dos tipos de papilomavírus bovino (BPV) de acordo com a procedência da amostra, localização e morfologia dos papilomas analisados

\begin{tabular}{cccccc}
\hline \multirow{2}{*}{ Rebanho Animal } & \multirow{2}{*}{ Amostra } & \multicolumn{2}{c}{ Papiloma } & \multirow{2}{*}{ Tipo BPV } \\
\cline { 3 - 4 } & & & Aspecto & Localização & \\
\hline \multirow{2}{*}{1} & A & LVA 1 & Filiforme & Pescoço & BPV-2 \\
& & LVA 2 & Pedunculado & Dorso & BPV-2 \\
2 & B & LVA 3 & Filiforme & Teto & BPV-6 \\
3 & C & LVA 4 & Filiforme & Teto & BPV-6 \\
& D & LVA 5 & Filiforme & Cabeça & BPV-6 \\
& & LVA 6 & Pedunculado & Teto & BPV-6 \\
& E & LVA 7 & Pedunculado & Tórax & BPV-6 \\
4 & F & LVA 8 & Pedunculado & Pescoço & BPV-1 \\
& & LVA 9 & Pedunculado & Escápula & BPV-2
\end{tabular}

\section{RESULTADOS}

A amplificação do fragmento esperado com 478 pb foi obtida nas nove amostras de papiloma cutâneo examinadas. A análise das sequiências das amostras do BPV possibilitou a identificação do BPV do tipo 2 (LVA-1, 2 e 9), do BPV-1 (LVA-8) e do BPV-6 (LVA-3, 4, 5 , 6 e 7). O Quadro 2 apresenta a distribuição dos tipos de BPV encontrados em relação à amostragem analisada, localização e característica macroscópica da lesão cutânea. O BPV-6 foi encontrado tanto em lesões localizadas no teto quanto em outras regiões do corpo. Em um animal $(\mathrm{F}$; amostras LVA8 e LVA9), foi possível detectar infecção

Quadro 3. Matriz de identidade entre as seqüências de nucleotídeos de um fragmento do gene L1 do BPV, obtidas a partir de lesões cutâneas (LVA) em bovinos, e as sequiências do BPV 1 a 6 (GenBank)

\begin{tabular}{ccccccc}
\hline Amostra & BPV-1 & BPV-2 & BPV-3 & BPV-4 & BPV-5 & BPV-6 \\
\hline LVA1 & 85,6 & $\mathbf{9 9 , 3}$ & 59,5 & 57,6 & 64,4 & 59 \\
LVA2 & 85,6 & $\mathbf{9 9 , 3}$ & 59,5 & 57,6 & 64,4 & 59 \\
LVA3 & 57,6 & 59 & 70,4 & 69,4 & 53,6 & $\mathbf{1 0 0}$ \\
LVA4 & 57,6 & 59 & 70,4 & 69,4 & 53,6 & $\mathbf{1 0 0}$ \\
LVA5 & 57,6 & 59 & 70,4 & 69,4 & 53,6 & $\mathbf{1 0 0}$ \\
LVA6 & 57,6 & 59 & 70,4 & 69,4 & 53,6 & $\mathbf{1 0 0}$ \\
LVA7 & 57,6 & 59 & 70,4 & 69,4 & 53,6 & $\mathbf{1 0 0}$ \\
LVA8 & $\mathbf{9 9 , 3}$ & 84,7 & 56,5 & 56,7 & 65,3 & 53,4 \\
LVA9 & 85,1 & $\mathbf{9 7 , 7}$ & 59,2 & 57,4 & 64,9 & 58,5 \\
& & & & & &
\end{tabular}

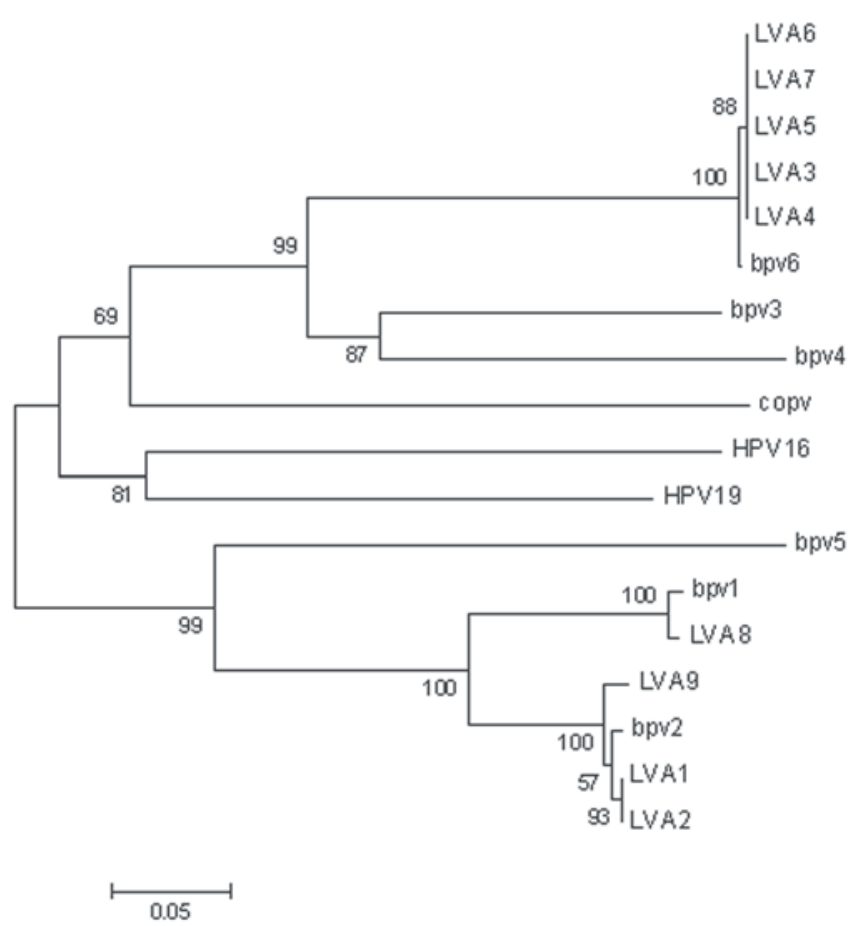

Fig.1. Árvore filogenética construída pelo método de distância utilizando o modelo evolutivo Kimura 2 - parâmetro e o algoritmo de agrupamento de vizinhos (neighbor-joining) com suporte de bootstrap para 1000 réplicas, a partir de um produto do gene L1 do papilomavírus amplificado pela PCR com primers degenerados (FAP59 e FAP64), incluindo nove amostras de papilomavírus bovino (LVA) identificadas no norte do Estado do Paraná e estirpes padrão de papilomavírus bovino (BPV-1 a 6); humano (HPV-16 e 19) e canino (COPV). 
concomitante com dois tipos de papilomavírus (BPV-1 e BPV2).

O Quadro 3 apresenta a matriz de identidade dos produtos amplificados em relação às estirpes padrão do BPV-1 a 6 disponíveis no GenBank. Todas as amostras do BPV-6 apresentaram $100 \%$ de identidade entre si com a amostra padrão utilizada para a análise. A figura 1 apresenta a árvore filogenética incluindo as nove amostras do BPV analisadas, os seis tipos padrão do BPV, o HPV-16 e 19, e o COPV.

\section{DISCUSSÃO}

A amplificação parcial do gene L1 dos papilomavírus de origem humana e animal, utilizando-se primers degenerados em PCR e posterior sequienciamento e análise filogenética, tem se apresentado como a principal estratégia para a identificação dos tipos de PV presentes em lesões cutâneas. Além da identificação dos tipos virais já descritos, essas estratégias têm ainda proporcionado a identificação de supostos novos tipos virais em várias espécies animais e em humanos (Forslund et al. 1999, Antonsson \& Hansson 2002, Ogawa et al. 2004).

A epidemiologia molecular das infecções pelos $\mathrm{PV}$ possui importância na profilaxia das infecções, uma vez que a imunidade é tipo-específica (Nicholls \& Stanley, 2000). Em humanos já foram descritos mais de 200 tipos do HPV, demonstrando a diversidade dessa família viral (Bernard 2005). Em bovinos, são conhecidos até o presente apenas seis tipos do BPV (Ogawa et al. 2004). Porém, esse número restrito provavelmente reflete mais uma falha na determinação dos tipos realmente presentes em infeç̧ões do que a não ocorrência de diversidade antigênica e molecular no BPV.

Antonsson \& Hansson (2002) na Suécia, utilizando os primers FAP59 e FAP64, identificaram cinco supostos novos tipos de BPV. No Japão, Ogawa et al. (2004) identificaram mais 10 supostos tipos, demonstrando que, a exemplo do HPV, a diversidade de tipos do BPV também pode ser bastante ampla. Portanto, esse número pequeno parece ser reflexo de falha metodológica na determinação dos tipos presentes em infecções, e não da inexistência de diversidade antigênica e molecular em BPV.

No Brasil, independentemente do nível de tecnificação da exploração pecuária, a infecção pelo BPV pode ser encontrada em rebanhos bovinos de corte e, principalmente, nos de aptidão leiteira em praticamente todo o país. Apesar da alta frequiência da infecção, a determinação dos tipos virais circulantes nos rebanhos ainda é bastante esporádica.

Nos estudos envolvendo amostras brasileiras foi possível detectar a infecção pelo BPV-1 em papilomas cutâneos, sangue, placenta e líquido aminiótico, o que pode sugerir a possibilidade de transmissão vertical (Santos et al. 1998, Freitas et al. 2003). O DNA do BPV-2 já foi detectado em amostras de sangue total, em tumores de bexiga de animais exibindo sinais clínicos de hematúria enzoótica, assim como em tecido do trato reprodutivo e em gametas (Carvalho et al. 2003, Wosiacki et al. 2005, 2006)

No presente trabalho, a utilização dos primers degenerados FAP59 e FAP64, seguida do seqüenciamento e análise filogenética dos produtos amplificados, possibilitou a deter- minação do tipo viral em todos os nove papilomas cutâneos analisados.

O BPV-2 tem sido universalmente relacionado com tumores epiteliais benignos e com o carcinoma da bexiga urinária, que ocasiona o quadro clínico de hematúria enzoótica (Campo 1995, Schuch 1998). Das três amostras (LVA1, 2 e 9) de BPV-2 identificadas no presente estudo, duas (LVA1 e 2) estavam presentes no mesmo animal. Porém, essas amostras foram provenientes de locais distintos do corpo (pescoço e dorso) e apresentavam morfologia distinta, sendo uma filiforme (LVA1) e outra pedunculada (LVA2), demonstrando que o mesmo tipo viral pode determinar lesões cutâneas com localização e aspecto distintos. Apesar das três amostras de BPV-2 apresentarem de $99,3 \%$ a $97,7 \%$ de identidade com a estirpe padrão utilizada para a análise filogenética, a comparação das amostras de BPV-2 provenientes de diferentes animais (A e F) demonstrou que a identidade entre elas foi de $98,4 \%$. Esse resultado caracteriza a presença de diversidade molecular entre estirpes de BPV provenientes de diferentes rebanhos.

Uma amostra (LVA8) apresentou 99,3\% de identidade com o BPV-1. A identificação do BPV-1 no animal F possibilitou a caracterização de infecção por dois tipos virais no mesmo animal, uma vez que no papiloma retirado da região escapular desse animal (LVA9) foi identificado como BPV-2.

O BPV-6 foi o tipo viral identificado com maior frequiência nesse estudo. Ressalta-se que esse resultado pode não refletir a maior prevalência desse tipo viral em lesões cutâneas em bovinos, mas pode ter sido originado pelo direcionamento da amostragem. O BPV-6 tem sido, com frequiência, relacionado com papilomas localizados no úbere e nos tetos. As cinco amostras identificadas como BPV-6 eram provenientes de quatro animais, três dos quais apresentavam lesões papilomatosas no úbere e nos tetos. No animal $\mathrm{D}$, que além dos papilomas presentes no aparelho mamário também apresentava papilomas cutâneos pedunculados em outras partes do corpo, foi possível a identificação do BPV-6 em um fragmento de papiloma pedunculado retirado do dorso. Esse resultado sugere que o padrão de localização e o aspecto da lesão, que em algumas situações já foi utilizado para definir o tipo de $\mathrm{BPV}$, pode não ser conclusivo e deve ser interpretado com cautela. $\mathrm{O}$ resultado obtido no animal $\mathrm{E}$, que não apresentava papilomas no úbere/tetos e no qual foi identificado o BPV6 em um fragmento de papiloma retirado do dorso, reforça essa afirmação. Todas as cinco amostras identificadas como BPV-6 apresentaram $100 \%$ de identidade entre si e com o vírus padrão utilizado para a análise filogenética.

Estudos relacionados com a determinação de tipos do BPV causadores de lesões cutâneas; correlação do tipo viral com a patologia da lesão e identificação de infeç̧ões mistas, ainda não foram realizados no rebanho bovino brasileiro. Esse trabalho demonstrou a diversidade de tipos de BPV presentes na região estudada, uma vez que três diferentes tipos virais foram encontrados em apenas nove amostras de papilomas. Foi ainda possível identificar diferenças de identidade dos BPV2 identificados. Os principais grupos internacionais que realizam pesquisas com o BPV têm dado ênfase ao desenvolvimento de vacinas para o controle das infecções, tanto cutâneas 
quanto em mucosas, como a hematúria enzoótica bovina e o carcinoma do trato digestório superior (Campo 1995). Novos estudos, utilizando amostras provenientes de outras regiões do país são necessários com o objetivo principal de caracterizar a epidemiologia molecular dos BPVs circulantes nos rebanhos bovinos brasileiros. Os resultados poderão delinear o desenvolvimento de medidas específicas de controle e profilaxia dessas infecções.

Agradecimentos.- Os recursos financeiros utilizados para a realização desse trabalho foram obtidos nas seguintes agências de fomento a pesquisa: CNPq, CAPES, FINEP e Fundação Araucária (FAP/PR). Alfieri, A.A. e Alfieri, A.F. são bolsistas produtividade do CNPq.

\section{REFERÊNCIAS}

Alfieri A.A., Parazzi, M.E., Takiuchi E., Médici K.C. \& Alfieri A.F. 2006. Frequency of group A rotavirus in diarrhoeic calves in Brazilian cattle herds, 19982002. Trop. Anim. Health Prod. 38:521-526.

Antonsson A., Forslund O., Ekberg H., Sterner G. \& Hansson B.G. 2000. The ubiquity and impressive genomic diversity of human nature of these viruses. J. Virol. 74 (24):11636-11641.

Antonsson A. \& Hansson B.G. 2002. Healthy skin of many species harbors papilomaviruses which are closely related to their human counterparts. J. Virol. 76 (24):12537-12542.

Bernard H.U. 2005. The clinical importance of the nomenclature, evolution and taxonomy of human papillomaviruses. J. Clin. Virol. 32:1-6.

Bloch N., Sutton R.H., Breen M. \& Spradbrow P.B. 1997. Identification of papillomavirus in scrapings from bovine warts by use of the polymerase chain reaction. Vet. Res. Commun. 21 (1):63-68.

Boom R., Sol C.J.A., Salimans M.M.M., Jansen C.L., Wertheim-Van Dillen P.M.E. \& Noordaa J. Van Der. 1990. Rapid and simple method for purification of nucleic acids. J. Clin. Microbiol. 28:495-503.

Borzacchiello G., Ambrosio V., Galati P., Poggiali F., Venuti A. \& Roperto F. 2001. The pagetoid variant of urothelial carcinoma in situ of urinary bladder in a cow. Vet. Pathol. 38(1):113-116.

Campo M.S. \& Jarrett W.F. 1986. Papillomavirus infection in cattle: viral and chemical cofactors in naturally occurring and experimentally induced tumours. Ciba Found Symposium 120:117-135.

Campo M.S., Jarrett W.F.H., Barron R., O'Neil B.W. \& Smith K.T. 1992. Association of bovine papillomavirus type 2 and bracken fern with bladder cancer in cattle. Canc. Res. 52:6898-6904.

Campo M.S. 1995. Infection by bovine papillomavirus and prospects for vaccination. Trends in Microbiol. 3:92-97.

Campo M.S. 1997. Review bovine papillomavirus and cancer. Vet. J. 54(3):175188.

Campo M.S. 1998. Persistent infection by bovine papillomavirus, p.503-516. In: Ahmed R. \& Chen I.S.Y. (ed.), Persistent Viral Infections. Wiley, Indianápolis.
Carvalho C., Freitas A.C., Brunner O., Góes L.G.B., Cavalcante A.Y., Beçak W. \& Santos R.C.S. 2003. Bovine papillomavirus type 2 in reproductive tract and gametes of slaughtered bovine females. Braz. J. Microbiol. 34(1):82-84.

David M.K., Peter M.H., Diane E.G., Robert A.L., Malcolm A.M., Bernard R. \& Stephen E.S. 2001. Fields Virology. $4^{\text {th }}$ ed. Lippincott Williams and Wilkins, Philadelphia.

De Villiers E-M., Fauquet C., Broker T.R., Bernard H.-U. \& Zur Hausen H. 2004. Classification of papillomaviruses. Virol. 324:17-27.

Forslund O., Antonsson A., Nordin P. \& Hansson B.G. 1999. A broad range of human papillomavirus types detected with a general PCR method suitable for analysis of cutaneous tumours and normal skin. J. Gen. Virol. 80:24372443.

Freitas A.C., Carvalho C., Brunner O., Birgel-Jr E.H., Dellalibera A.M.M.P., Benesi F.J., Gregory L., Beçak W. \& Santos R.C.S. 2003. Viral DNA sequences in peripheral blood and vertical transmission of the virus: a discussion about BPV-1. Braz. J. Microbiol. 34(1):76-78.

Hall T.A. 1999. BioEdit: a user-friendly biological sequence alignment editor and analysis program for Windows 95/98/NT. Nucleic Acids Symposium 41:95-98.

Hopkins N.C.G. 1986. Aetiology of enzootic haematuria. Vet. Rec. 118(26):715717.

Jelínek F. \& Tachezy R. 2005. Cutaneous papillomatosis in cattle. J. Comp. Pathol. 132:70-81.

Kumar S., Tamura K. \& Nei M. 2004. MEGA3: Integrated software for Molecular Evolutionary Genetics Analysis and sequence alignment. Brief Bioinform. 5(2):150-163.

Lancaster W.D. \& Olson C. 1982. Animal papillomaviruses. Microbiol. Res. 46 (2):191-207.

Nicholls, P.K. \& Stanley, M.A. 2000.The immunology of animal papillomaviruses. Vet. Immunol. Immunopathol., 73:101-127.

Ogawa T., Tomita Y., Okada M., Shinozaki H.K., Kaiho I. \& Shirasawa H. 2004. Broad-spectrum detection of papillomaviruses in bovine teat papilomas and health teat skin. J. Gen. Virol. 85:2191-2197.

Sambrook J. \& Russell D.W. 2001. Molecular Cloning: A Laboratory Manual. Cold Spring Harbor Laboratory, New York. 999p.

Santos R.C.S., Lindsey C.J., Ferraz O.P., Pinto J.R., Mirandola R.S., Benesi, F.J., Birgel E.H., Pereira C.A.B. \& Beçak W. 1998. Bovine papillomavirus transmission and chromosomal aberrations: an experimental model. J. Gen. Virol. 79(1):2127-2135.

Schuch L.F.D. 1998. Papilomatose bovina, p.115-118. In: Riet-Correa F., Schild A.L. \& Mendez del C. (ed.), Doenças de Ruminantes e Eqüinos. Editora Universitária, UFPel, Pelotas. 651p.

Wosiacki S.R., Barreiros M.A.B., Alfieri A.F. \& Alfieri A.A. 2005. Semi-NestedPCR for detection and typing of bovine papillomavirus type 2 in urinary bladder and whole blood from cattle with enzootic haematuria. J. Virol. Methods 126(1-2):215-219.

Wosiacki S.R., Claus M.C., Alfieri A.F. \& Alfieri A.A. 2006. Bovine papillomavirus type 2 detection in the urinary bladder of cattle with chronic enzootic haematuria. Mem. Inst. Oswaldo Cruz 101(6):635-638. 